\title{
JAMS 2010-2015: literature themes and intellectual structure
}

\author{
G. Tomas M. Hult ${ }^{1}$
}

Published online: 21 September 2015

(C) Academy of Marketing Science 2015

\begin{abstract}
This issue of the Journal of the Academy of Marketing Science (JAMS) is the final of my term as editor of the journal, although the next several issues will contain articles accepted during my time as editor. It has been a privilege to continue my predecessors' editorships, most immediately following David Stewart, and to now hand over the reins to Robert Palmatier, as my editorial successor. This editorial is a brief account of my JAMS editorial experiences and statistics, along with an overview of literature themes and the intellectual structure of the 2010-2015 articles in JAMS.
\end{abstract}

Keywords Marketing literature $\cdot$ Intellectual structure

\section{Introduction}

As my most obvious introductory remarks, I want to state that it has been an honor, delight, and eye-opening learning experience to process the 3089 new manuscripts that were submitted to JAMS between June 1, 2009, and May 31, 2015 (plus more than 1000 manuscripts in various stages and depths of revision rounds of review during this period). First-round manuscripts averaged $13.5 \%$ revise/resubmit and $86.5 \%$ reject decisions for the 6 years, and these revise/resubmit papers ultimately got accepted at a $62.7 \%$ rate. Overall, the editorial team was part of publishing 271 articles during 2010 to 2015 .

Table 1 shows a summary of the 2009 to 2015 statistics. The current year (2015) is a forecast based on May 31, 2015 data,

G. Tomas M. Hult

hult@msu.edu

1 Eli Broad College of Business, Michigan State University, East Lansing, MI 48864, USA the end of my term for processing submissions. As the avid JAMS reader knows, these statistics are updated via the social media platforms for JAMS on a continuous, periodic basis (e.g., Twitter, Facebook, LinkedIn). Table 1 shows that the journal had between 432 and 547 new submissions per year in the 2009-2015 period, averaged between 30.4 and 42.0 days in review for the first round (not including desk rejects), and had acceptance rates of $7.37 \%$ to $10.14 \%$ on an annual basis.

Later in this issue, we include the complete list of reviewers who provided service during the 2009 to 2015 period of my editorship. The Area Editors and Editorial Review Board members are also printed on the masthead of the journal. On behalf of myself and Anne Hoekman, I sincerely want to thank each of these scholars for their valuable service to $J A M S$ and the marketing professorate. And, I personally want to say, in print, THANK YOU to Anne Hoekman, JAMS Managing Editor, for her amazing, diligent, and extraordinary service to JAMS.

During our editorial period, Anne and I put the journal front and center in transparency, we think, by engaging fully and proactively on social media. Yes, we know, a few years from now social media will either seem like a given in all quarters of academic publishing or perhaps archaic because there is something better out there. But, at the time we took over the journal in 2009, none of the social media accounts existed for JAMS (and very few journals engaged in social media to do knowledge generation, dissemination, and to engage the professorate). From its start as a new business for JAMS in 2009, the LinkedIn group for JAMS now has 4467 members (September 1, 2015), and Twitter and Facebook are also heavily used by the marketing professorate to interact with JAMS and our community.

In crystalizing our editorial period, we think a focus on social media, fast and good processing of submissions, active promotion of articles via various vehicles, and ensuring that $J A M S$ was everywhere all contributed to great reception among the marketing professorate. The JAMS impact factor 
Table 1 JAMS statistics, 2009-2015

\begin{tabular}{llllllllll}
\hline Year & $\begin{array}{l}\text { New } \\
\text { submissions }\end{array}$ & $\begin{array}{l}\text { Desk } \\
\text { rejects }\end{array}$ & $\begin{array}{l}1^{\text {st }} \text { review } \\
\text { (days) }\end{array}$ & $\begin{array}{l}2^{\text {nd }} \text { review } \\
\text { (days) }\end{array}$ & $\begin{array}{l}3^{\text {rd }} \text { review } \\
\text { (days) }\end{array}$ & $\begin{array}{l}\text { Articles } \\
\text { printed }\end{array}$ & $\begin{array}{l}\text { Theory } \\
\text { articles }\end{array}$ & $\begin{array}{l}\text { Pages } \\
\text { printed }\end{array}$ & $\begin{array}{l}\text { Acceptance } \\
\text { rate }\end{array}$ \\
\hline $2015^{*}$ & 519 & $60.2 \%$ & 35.2 & 29.8 & 12.5 & 42 & $9.5 \%$ & 820 & $8.09 \%$ \\
2014 & 547 & $52.8 \%$ & 37.2 & 28.8 & 9.3 & 41 & $19.5 \%$ & 701 & $7.50 \%$ \\
2013 & 543 & $42.9 \%$ & 34.9 & 29.5 & 12.1 & 40 & $5.0 \%$ & 736 & $7.37 \%$ \\
2012 & 512 & $39.1 \%$ & 33.9 & 29.6 & 9.9 & 48 & $16.0 \%$ & 844 & $9.38 \%$ \\
2011 & 513 & $37.1 \%$ & 30.5 & 22.6 & 4.5 & 52 & $25.0 \%$ & 941 & $10.14 \%$ \\
2010 & 476 & $30.9 \%$ & 30.4 & 28.7 & 10.1 & 48 & $10.4 \%$ & 806 & $10.08 \%$ \\
2009 & 432 & $23.3 \%$ & 42.0 & 40.8 & 17.0 & 34 & $11.8 \%$ & 575 & $7.87 \%$ \\
\hline
\end{tabular}

New submissions refer to manuscripts first submitted to $J A M S$ for original review (this does not include revisions). Desk rejects refer to the percentage of submission that are not sent out for review to a review team; these are rejected without review by the editor. 1st, 2nd, and 3rd review refer to the number of days, on average, manuscripts in various stages of the review process take for an editorial decision. Articles printed refer to the number of articles printed in the journal in a given year. Theory articles refer to the percentage of articles published in a given year which are not based on data (i.e., they are theoretical and/or conceptual in scope). Pages printed are the total number of pages printed in the journal in a year. Acceptance rate was calculated as the number of articles printed in the journal in a year divided by the number of new submissions received between January 1 and December 31 in a year

*The 2015 data was forecasted on May 31, 2015

in Thomson Reuter's Web of Science Journal Citation Reports improved over the editorial period from 1.578 in 2009 to 3.818 in 2015. From 2010 to 2015 , JAMS ranked among the top three premier marketing journals in each year. As a breadth journal covering all aspects of marketing-perhaps with a slight skewness toward managerial articles - these impact scores and rankings are a tribute to the wide exposure $J A M S$ has in the field. By all accounts, all relevant measures of performance speak to a solid placement of JAMS in the marketing literature.

Building on this breadth (and depth) of coverage of JAMS articles along with the theoretical rigor and practical relevance that we have focused on, my period as editor was signified by the following statement that I developed for the journal:

\section{JAMS is a top journal choice for scholars seeking to publish their highest quality, theoretically sound, and managerially relevant research in marketing.}

This positioning was created with the history of the journal in mind, with its then present focus in 2009, and with an outlook toward the future as one of marketing's premier journals. In the same spirit, my last commentary as editor-beyond these introductory thoughts - is focused on (1) literature themes during the 2010-2015 period and (2) the intellectual structure during the 2010-2015 period, as well as some parting thoughts.

\section{Literature themes in JAMS, 2010-2015}

All journals have or adopt a position in the marketplace that make them unique. With the proliferation of marketing journals, this strategic positioning is becoming more and more difficult. This holds especially true for $J A M S$, which is by design a breadth journal covering all aspects of marketing. A curious or diligent reader will find that we published on virtually all areas of marketing using most available contemporary methodologies during 2010 to 2015. However, whether due to editorial influence (I hope not), interest on the part of certain segments of the marketing professorate to publish in the journal, or a de facto brand positioning among marketing journals, JAMS published in certain areas more than others during 2010 to 2015.

Table 2 provides a summary of prevalent themes emerging from the highly cited articles in JAMS during 2010 to 2015. Each year is represented as a standalone data point to account for citation differences due to age, and then the topics are emerging across years. Jeannette Mena, University of South Florida, kindly assisted in compiling the information for Table 2. She has developed a unique expertise in conducting literature reviews and was also a coauthor of the top-cited article - a review and assessment article-during my time as editor (i.e., Hair, Sarstedt, Ringle, and Mena, 2012). Having Jeannette assist in this analysis allowed for some editorial distance to the analysis and an objective take on the literature.

In the analysis, nine prevalent themes emerge as the most influential (so far) of the articles published in 2010 to 2015 in JAMS. These include (in no particular order):

- International marketing and international competitiveness

- Marketing communications and brands

- Personal selling and sales management 


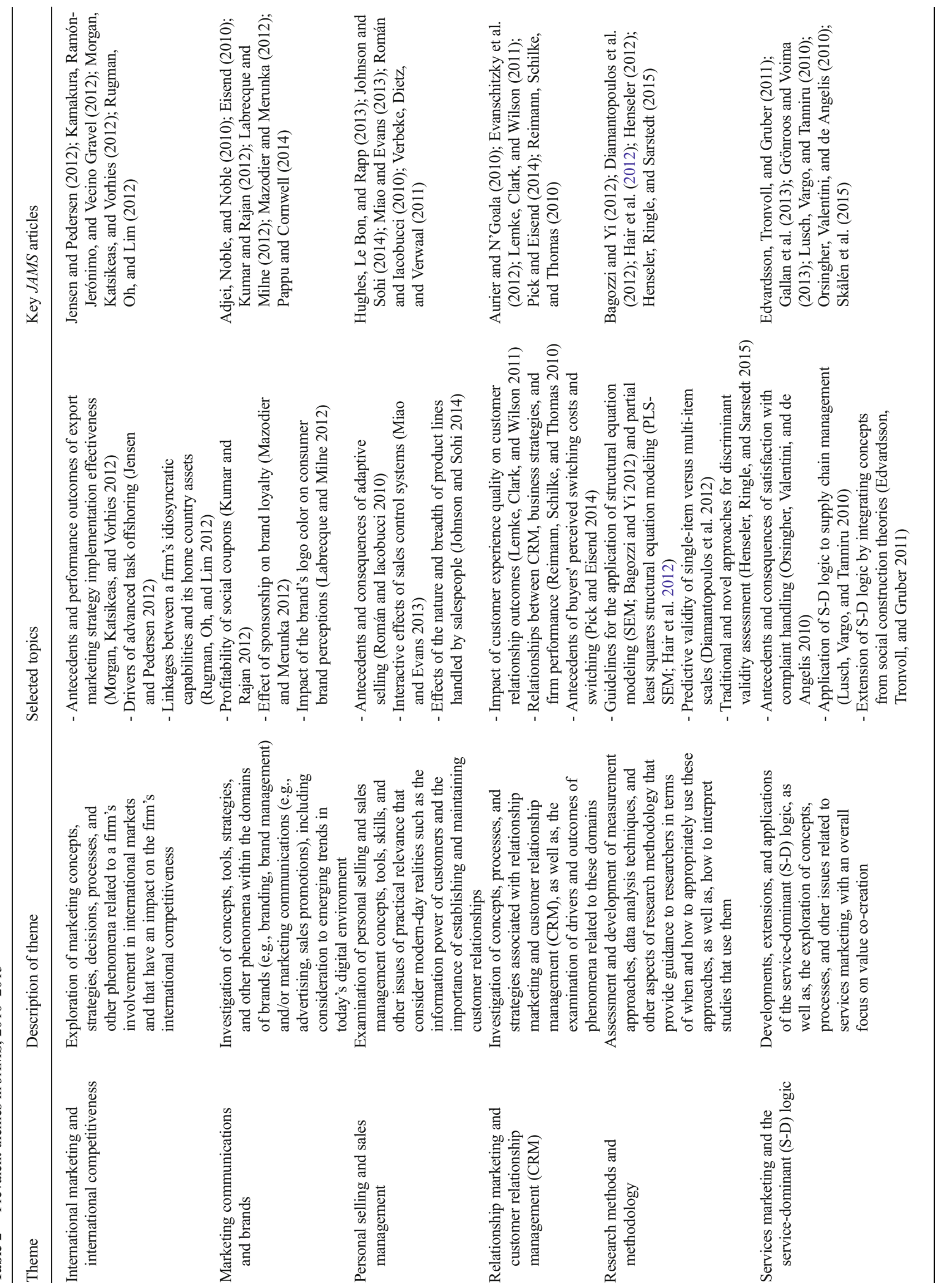




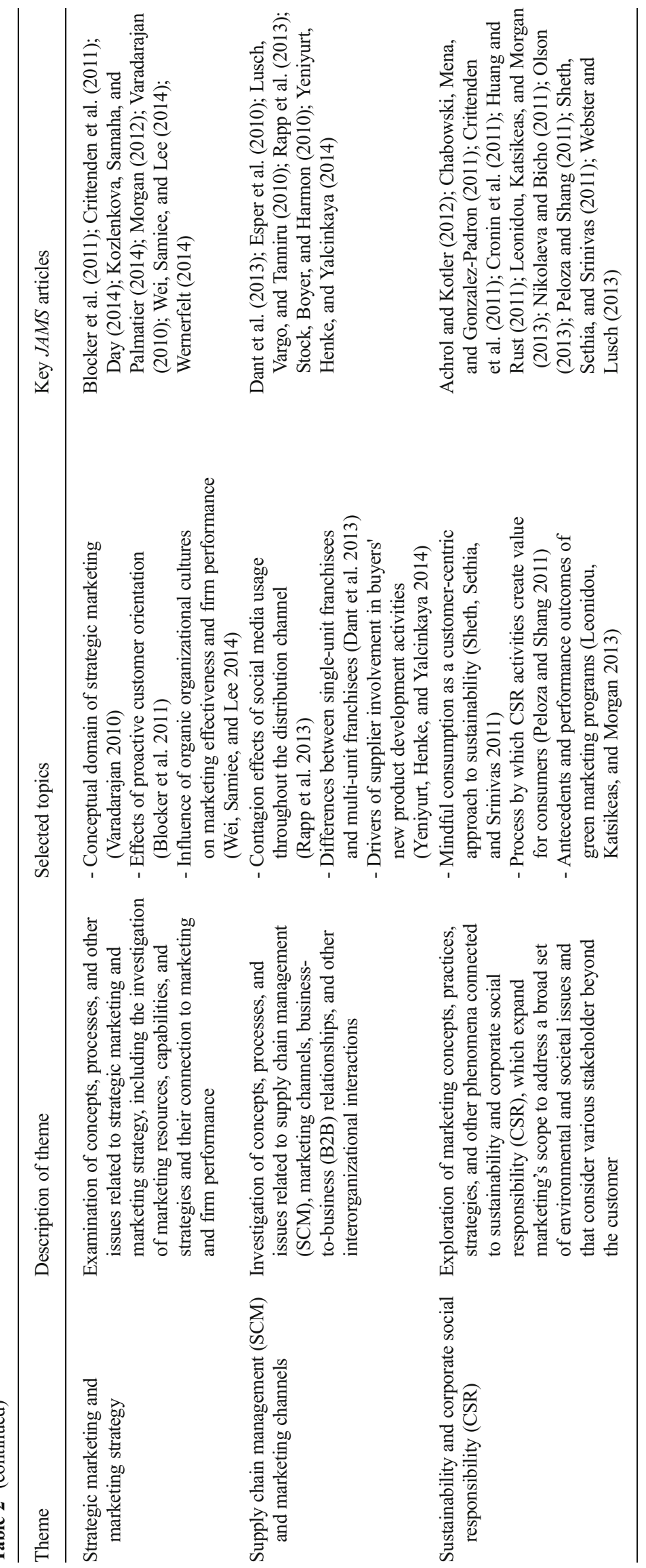


- Relationship marketing and customer relationship management

- Research methods and methodology

- Services marketing and the service-dominant logic

- Strategic marketing and marketing strategy

- Supply chain management and marketing channels

- Sustainability and corporate social responsibility.

The description of the themes, selected topics covered for each theme, and key JAMS articles during the 2010 to 2015 period are included in Table 2. The JAMS articles listed in Table 2 can be found in the journal during 2010 to 2015 and are therefore not included in the reference list.

A wealth of analysis, discussion, and implications could be drawn from Table 2. However, I will leave it to the marketing professorate to engage in this interpretation. Instead, my objective here is to include a summary of the prevalent themes in JAMS during 2010 to 2015 as a historical record for the journal and the topics covered in a premier journal in marketing in this period.

Whether the topic coverage, positioning, or journal's brand stay the same over the next editorial periods is an interesting focus to consider. The answer may depend on editorship to some degree but likely more on where the field is heading in the future. The future often rests in the past-at least the theoretical foundations of the past. In that vein, I wanted to include a section of this editorial on the intellectual structure that we have seen during 2010 to 2015 .

\section{Intellectual structure in $J A M S$, 2010-2015}

To evaluate the intellectual structure of the most influential (cited) JAMS articles published in 2010 to 2015, citation data from the articles citing the top $30 J A M S$ articles were collected from the Web of Science (WOS) database. The JAMS articles listed in Fig. 1 can be found in the journal during 2010 to 2015 and are therefore not included in the reference list. Similar to the analysis of literature themes, I added an independent voice to the intellectual structure analysis. Brian Chabowski, University of Tulsa, kindly assisted in compiling and analyzing the data for Fig. 1, providing some objectivity regarding the analysis.

As is a customary process in bibliometric analyses evaluating the intellectual structure of a literature domain, 843 published articles were identified in the WOS database that were used in the selected JAMS articles. From this set, 71,808 citations were used in the analysis to establish the visual representation of the most cited JAMS articles in 2010 to 2015. The well-read scholar likely knows that Brian Chabowski has published co-citation data-based multidimensional scaling studies in a variety of premier journals on a number of topics areas, and I encourage interested readers to take a deeper look at the methodology in those outlets (e.g., Chabowski et al. 2011; Chabowski et al. 2013).

Based on the co-citation data gathered, multidimensional scaling (MDS) was used to plot and examine the top 30 JAMS articles in further detail. As noted on the MDS map in Fig. 1, the JAMS articles were clustered based on their proximity and interconnectedness using standardized distances. Therefore, the more JAMS pieces that were cited together by the same articles in the database, the closer proximity of the JAMS articles. The result is that many articles link together to form large, overarching clusters focusing on general research topics. The terms used to identify each cluster are based on the nature and content of the JAMS articles included in each cluster as well as the articles citing them.

To assess the goodness-of-fit of the data to the proximitybased model developed, a stress value of the MDS solution was calculated. Using this as a basis for model evaluation, stress values of 0.10 or less indicate a good model fit, stress values between 0.11 and 0.20 show fair model fit, and stress values greater than 0.20 indicate poor model fit. As such, a stress value of 0.12 in the JAMS modeling indicates a highly fair model fit to the co-citation data. This follows previous bibliometric evaluations of research domains.

In the analysis, four intellectual clusters emerge as the most critical foundations based on the articles published in 2010 to 2015 in JAMS. These include (in no particular order):

- Networks, consumers, and resources

- Market-focused sustainability

- Customer experience and co-creation

- Methods, service, selling, and channels

As with the literature themes, a wealth of analysis, discussion, and implications could be drawn from Fig. 1 on the most obvious intellectual structure "clusters" in JAMS in 2010 to 2015. But, overall, I will leave it to the marketing professorate to engage in this interpretation. The historical take on the journal and intellectual clusters covered in a premier journal in marketing in this period is a more important focus.

That said, briefly, it is interesting to note that networks and resources cluster together with consumers. Perhaps this is an avenue to bridge scholarship in managerial domains of marketing with consumer research. This idea of managerial implementation and consumers is emphasized also in the "customer experience and co-creation" cluster. The most general, perhaps disjointed, cluster is "methods, service, selling, and channels." The broad implication may be that in a service dominant economy, perhaps even service dominant logic, selling-related issues combine with channels to drive knowledge generation with sophisticated methods. 


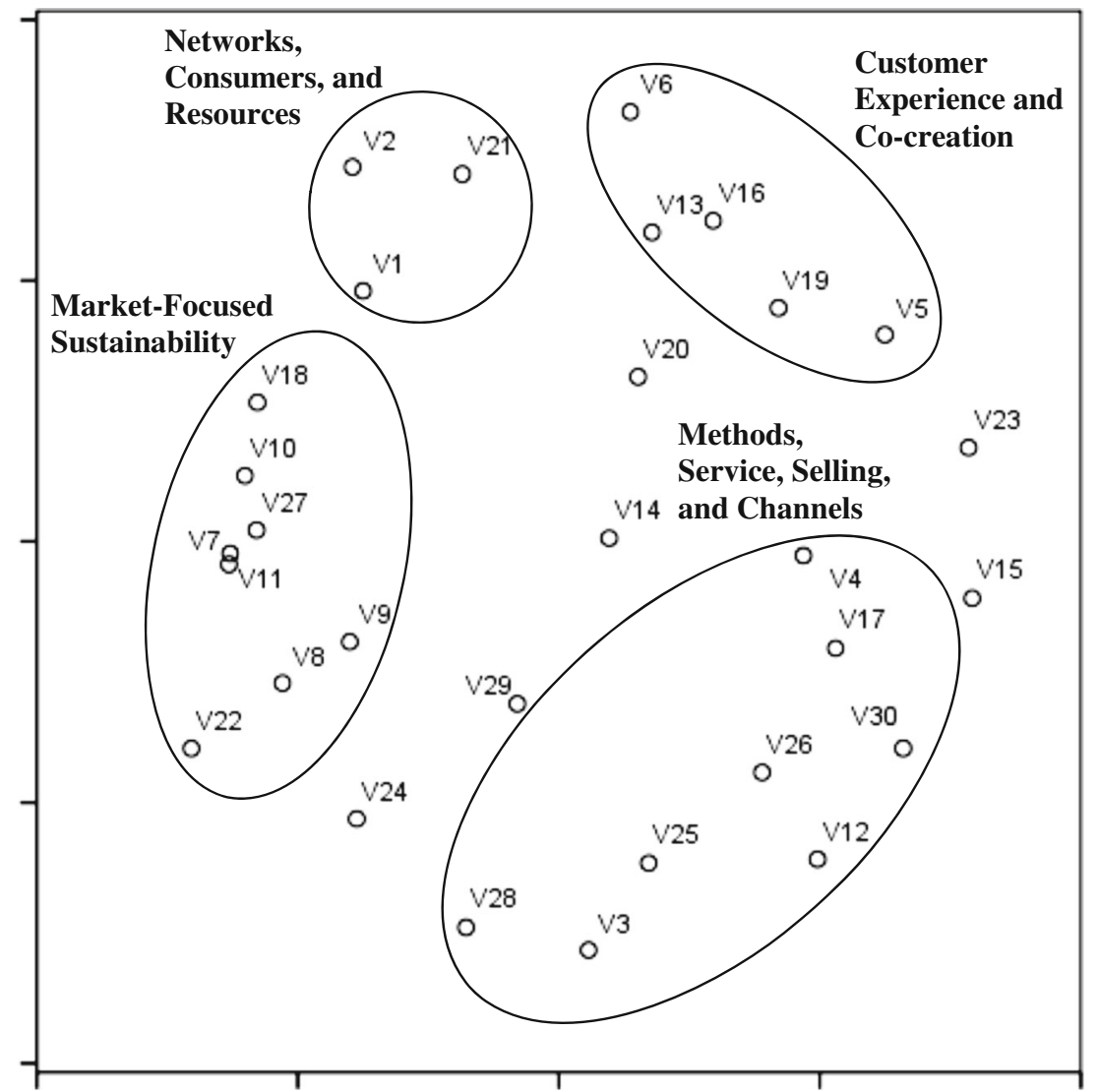

Fig. 1 Intellectual structure of $J A M S, 2010-2015$. Stress value $=0.12 ; *$ data gathered from Web of Science on June 19, 2015. JAMS Articles: V1 = Achrol and Kotler 2012; V2 = Adjei, Noble, and Noble 2010; V3 = Aurier and N'Goala 2010; V4 = Bagozzi and Yi 2012; V5 = Blocker et al. 2011; V6 = Cadwallader et al. 2010; V7 = Chabowski, Mena, and Gonzalez-Padron 2011; V8 = Closs, Speier, and Meacham 2011; V9 = Connelly, Ketchen, and Slater 2011; $\mathrm{V} 10=$ Crittenden et al. 2011; V11 = Cronin et al. 2011; V12 = Diamantopoulos et al. 2012; V13 = Edvardsson, Tronvoll, and

But to me the most intriguing intellectual cluster that was formed in Brian's analysis is that on "market-focused sustainability." Not only was sustainability the topic focus for a special issue of JAMS during my editorship, but "market-focused sustainability" was also the core of the title of my editorial to the issue. (So, there is a reason I was not conducting the co-citation multidimensional scaling analysis of the intellectual clusters in the journal during my time period; it may have been less believable as an intellectual cluster if I had done the analysis.) "Market-focused sustainability" being one of four core intellectual clusters during 2010 to 2015 may indicate the role of the editor, albeit small, in setting the tone for research in a field.

\section{Parting thoughts}

O.C. Ferrell and I noted in the editorial to the 40th anniversary issue of JAMS (Hult and Ferrell 2012) that the Academy of
Gruber 2011; V14 = Esper et al. 2010; V15 = Gregoire, Laufer, and Tripp 2010; V16 = Gronroos and Voima 2013; V17 = Hair et al. 2012; V18 = Hult 2011; V19 = Lemke, Clark, and Wilson 2011; V20 = Lusch, Vargo, and Tanniru 2010; V21 = Murray, Gao, and Kotabe 2011; V22 = Nikolaeva and Bicho 2011; V23 = Orsingher, Valentini, and de Angelis 2010; V24 = Peloza and Shang 2011; V25 = Reimann, Schilke, and Thomas 2010; V26 = Roman and Iacobucci 2010; V27 = Sheth, Sethia, and Srinivas 2011; V28 = Stock, Boyer, and Harmon 2010; V29 = Varadarajan 2010; V30 = Verbeke, Dietz, and Verwaal 2011

Marketing Science began in 1971, JAMS was conceptualized in 1972, and the journal started publishing in 1973 - all under the leadership of Dr. Harold Berkman. With this wealth of history, it's been a unique role to be in as JAMS editor, again having my dissertation chair and mentor O.C. Ferrell as my "boss," as the Vice President of Publications for AMS. O.C., thank you for your incredible support, professional guidance, and superb friendship!

I want to conclude and reiterate that it has been a delight, privilege, and honor to serve AMS, the marketing professorate, and the Journal of the Academy of Marketing Science as the 11th editor in its 43-year history. Journal editors serve as gatekeepers in some respect to journal publication but, more so, they serve as caretakers of intellectual knowledge, the journal's brand, and the journal as an historical institution. I hope my facilitator role as editor has been a value to the field of marketing scholarship and the marketing professorate. Thank you for the opportunity! 


\section{References}

Chabowski, B. R., Samiee, S., \& Hult, G. T. M. (2013). A bibliometric analysis of the global branding literature and a research agenda. Journal of International Business Studies, 44(6), 622-634.

Chabowski, B. R., Mena, J. A., \& Gonzalez-Padron, T. L. (2011). The structure of sustainability research in marketing, 1958-2008: a basis for future research opportunities. Journal of the Academy of Marketing Science, 39(1), 5570 .
Hair, J. F., Sarstedt, M., Ringle, C. M., \& Mena, J. A. (2012). An assessment of the use of partial least squares structural equation modeling in marketing research. Journal of the Academy of Marketing Science, 40(3), 414-433.

Hult, G. T. M. (2011). Market-focused sustainability: market orientation plus! Journal of the Academy of Marketing Science, 39(1), 1-6.

Hult, G. T. M., \& Ferrell, O. C. (2012). A tribute to forty years of top-level marketing research. Journal of the Academy of Marketing Science, 40(1), 1-7. 